\title{
Adaptation to Climate Change: Context Matters
}

ROSINA BIERBAUM, PHD, AND MISSY STULTS

Volume 1, Fall 2013

DOI: http://dx.doi.org/10.3998/mjs.12333712.0001.004

\section{ABSTRACT}

Coping with climate change in the coming decades will require innovation in planning and management of natural, social, economic, and built systems. While assessment of climate-related vulnerability and risk is advancing, little has been done to implement adaptation strategies across regions and sectors. As more entities begin undertaking climate adaptation activities, it becomes more important than ever to involve a diverse array of stakeholders in characterizing the questions that need to be answered, the problems most necessary to solve, and the adaptation options that are feasible and desirable. This type of engagement may help accelerate the pace of planning and action needed to insure that communities can protect people and property as climate changes. Achieving this engagement model will require removing a number of barriers but will provide a rich research agenda for universities, industry, and government.

\section{Introduction}

Recently released reports from the US National Academies (National Research Council 2010), the US Global Change Research Program (Karl, Melillo, and Peterson 2009), the Intergovernmental Panel on Climate Change (IPCC) (IPCC 2007), the United Nations (Bierbaum et al. 2007a), and the World Bank (Potsdam Institute for Climate Impact Research and Climate Analytics 2012; World Bank 2010) underscores the recognition that humans are rapidly changing the climate. Globally, the average surface temperature is now approximately $1.5^{\circ} \mathrm{F}$ above its level in 1750 (NASA 2013) with most of the increase having occurred since 1970. Moreover, the 12 warmest years on record for global temperature have all occurred since 1997 (United King- 
dom Meteorological Office 2013). In the United States, 2012 set the record for the warmest year ever in the 48 continental states (NOAA 2013). These changes in temperature will continue to have significant impacts on ecosystems and human society, in many cases taxing the ability of built, social, and natural systems to cope.

In addition to temperature change, more intense droughts and storms, increased wildfire, heat waves, rising sea levels, damaging storm surges, and shifting ranges suitable for plants and animals are all examples of impacts already being experienced and projected to become more frequent or severe due to climate change (US Global Change Research Program 2013a). For example, today's plant hardiness zones in Michigan are more like those found in Kentucky in 1990 (Arbor Day Foundation 2013). In the coming decades, annual temperatures in the state of Massachusetts are expected to be comparable to current annual temperatures in South Carolina (US Global Change Research Program 2013a). Parts of Texas could endure more than four months of temperatures over $100^{\circ} \mathrm{F}$ (US Global Change Research Program 2013a). Twenty-eight official state trees and flowers will likely no longer live in those states by the end of the century (National Wildlife Federation 2007). Maples are migrating north to Canada, affecting US fall foliage and maple syrup production (Frumhoff et al. 2007). And extreme weather events are causing and will likely continue to cause major public health issues, ranging from death to personal injury to aggravation of chronic diseases to heightened mental health concerns (Centers for Disease Control and Prevention 2013; Gifford 2011).

Since past is no longer an indication of the future, climate adaptation must become part of our ongoing planning and management processes. For too long, talking about adaptation or "coping with climate change" seemed to imply that no serious mitigation or emissions reductions were being contemplated. We now know that both mitigation (actions to reduce greenhouse gas emissions) and adaptation (actions to prepare for changes in climate) are needed (Bierbaum et al. 2007a; Intergovernmental Panel on Climate Change 2012). Therefore, a sensible strategy to minimize the damages from anthropogenic climate change must work simultaneously to mitigate the pace and ultimate magnitude of the changes that do occur and to adapt to the changes that cannot be avoided.

\section{The Role of Assessments}

A key step in adapting to climate change is understanding what is vulnerable and at risk in particular regions and sectors, knowing how climate change will interact 
with other socio-economic and environmental stressors, and identifying options to build near- and long-term resilience to current and projected changes. A number of efforts are underway to help meet these needs, but one particularly timely effort is the US National Climate Assessment (NCA). Since 1990, Congressional mandate has required periodic reports to the President, Congress, and the American people on the state of climate change science and observed and projected climate impacts across sectors and regions of the United States (United States Global Change Research Act 1990). These reports, known as the NCA, help characterize US vulnerability to climate change and are beginning to help identify strategies to build resilience across the public, private, governmental, and non-governmental communities. Two NCAs were completed in 2000 and 2008-2009 and a third is underway (slated for release in late 2013).

The law requires an NCA report "that integrates, evaluates, and interprets the findings of the US Global Change Research Program (USGCRP); analyzes the effects of global change on the natural environment, agriculture, energy production and use, land and water resources, transportation, human health and welfare, human social systems, and biological diversity; and analyzes current trends in global change, both human-induced and natural, and projects major trends for the subsequent 25 to 100 years" (United States Global Change Research Act 1990).

Each NCA has attempted to summarize the state of understanding about climate change impacts with varying sectoral and regional detail. The first NCA examined the impacts of climate change on 22 regions of the United States, beginning with extensive stakeholder workshops in each region (US Global Change Research Program 2000). The second NCA took a different approach and produced 21 climaterelated synthesis reports on various topics (Karl, Melillo, and Peterson 2009). The ongoing third NCA characterizes regional and sectoral impacts and begins to address the questions of how to advance adaptation at appropriate scales (US Global Change Research Program 2013a). In addition, the third NCA examines crosssector interactions, such as how competing demands for land, water, and energy may affect options available for both mitigation and adaptation (see Figure 1 for a list of the chapters under development).

More than 1,000 stakeholders have participated in workshops, analyses and reviews of the NCA reports over the last 15 years, helping to ensure that scientific research is linked with on-the-ground knowledge of local climatic changes (US Global Change Research Program 2013b). Unfortunately, many of the stakeholder collaborations built up as part of the first two NCA processes have had to be re-built due to a lack of sustained momentum and funding to support continued partner- 
Figure 1: Chapters in the 2013 National Climate Assessment

Climate Science I Water Resources I Energy Supply and Use I Transportation I Agriculture I Forestry I

Ecosystems and Biodiversity I Human Health I Water, Energy, Land Use I Urban, Infrastructure, Vulnerability I

Tribal, Indigenous, and Native Lands and Resources I Land Use / Land Cover Change I Rural Communities, Agriculture, and Development I Biogeochemical Cycles I Northeast I Southeast and Caribbean I Midwest I Great

Plains I Southwest I Northwest | Alaska and Arctic I Hawaii and Pacific Islands I Oceans and Marine Resources |

Coastal Zone, Development, and Ecosystems I Decision Support I Mitigation I Adaptation I Research Agenda for Climate Change Science I The NCA Long-Term Process

ships. In an effort to remedy this situation, the 2013 NCA has sought to maintain momentum by developing a strategy for a sustained assessment process with associated stakeholder engagement.

\section{The Role of Stakeholder Involvement in the NCA and Beyond}

Bringing together stakeholders to identify relevant challenges, lingering questions, and strategies for building resilience to climate change is pivotal in ensuring that solutions are contextually relevant, equitable, understandable, and effective. Growing recognition of the need for a new model of deep and long-term stakeholder engagement has emerged (Van Aalst, Cannon, and Burton 2008; Few, Brown, and Tompkins 2007). However, few examples of this new model have been successfully employed. Instead, traditional engagement techniques that focus on one-way information flow have dominated climate work to date. For example, in the first NCA, scientists provided agricultural communities information on likely average growing season temperatures when it turned out that dates of first and last frost, as well as temperatures at corn tasseling time, would have been more useful. It was only through direct engagement with stakeholders from the agricultural community that knowledge of specific local needs could have been obtained.

As the above example demonstrates, building local, regional, national, and private- and public-sector resilience towards climate change will likely depend on understanding the key concerns and desired outcomes of key stakeholders. Therefore, effective adaptation to climate change requires collaboration with multiple actors within a system of concern (i.e., water or energy) as well as looking for common concerns across multiple systems. Different approaches, thinking, and stakeholder engagement techniques may be necessary depending on the scale of adaptation actions. Regardless of the approach, stakeholder questions and needs are essential to characterizing what is vulnerable, what is actionable, and what is feasible to implement in order to increase resilience. 
Recognizing the importance of designing and defining adaptation options appropriate to particular regional contexts, two National Summits on Adaptation were convened in 2007 and 2009 to elicit stakeholder input for future adaptation efforts (Bierbaum, Brown, and McAlpine 2007b; National Climate Adaptation Summit Committee 2010). These conversations have informed an ongoing Interagency Climate Change Adaptation Task Force that is assessing what the federal government is doing to adapt to climate change and to develop recommendations for additional actions to support a national adaptation strategy (White House 2012). Summit participants representing industry, academia, environmental groups, and policymakers from city, state, regional, national, and international levels met and discussed the problems climate change will continue to pose to economic, environmental, and social operations. 2007 Summit participants focused on impacts and challenges posed by climate change relative to four sectors: energy, fisheries, public health, and water quality (Bierbaum, Brown, and McAlpine 2007b). In 2010, Summit participants focused on incentives and barriers to adaptation, knowledge needed to advance adaptation, and ways for local to national actors to enable adaptation (National Climate Adaptation Summit Committee 2010). Participants at both Summits emphasized that preparing for climate change requires fundamental changes in planning, management, institutional arrangements, and legal/regulatory levers. While these Summits succeeded in building awareness of the need for adaptation and instrumental in providing insights into what a national adaptation strategy should be, the real challenge has been finding ways to incorporate stakeholders into on-the-ground efforts to build more resilient communities.

\section{Adaptation within a Sector}

The impacts of climate change will vary across the country depending on factors such as local geography, existing flexibility in the system in question, and planning choices. For example, the energy sector in the Northeast has unique vulnerabilities when compared to the energy sector in the Gulf coast. In the Northeast, summer energy demand in recent years (2010) has already pushed the electricity grid past its designed capacity, creating an increased risk for power outages (Frumhoff et al. 2007). Continued increases in average temperature will likely lead to higher demand for summer cooling, placing further stress on an already over-taxed system (US Climate Change Science Program 2007). If this happens, loss of power could cause substantial public health effects, transportation shutdowns or delays, 
and significantly affect the regional economy (US Climate Change Science Program 2007). In order to address these potential impacts, utilities in the Northeast are embracing energy efficiency, demand-side management, and distributed generation, as well as adding redundancy to the energy supply system (Morgan, Apt, and Lave 2005; Solecki and Rosenzweig 2012).

In contrast, the primary weather/climate threat to the energy supply in the Gulf is risk from extreme weather events, most notably hurricanes. Extreme weather events can expose energy infrastructure to damaging wind, storm surge, and flooding, impacts that can debilitate the energy supply and distribution system. During Hurricanes Katrina and Rita, 111 of the 4,000 offshore oil and gas drilling platforms in the Gulf of Mexico were destroyed and 31 were damaged (Energy and Environmental Analysis, Inc. 2005). Approximately 90 percent of oil production and 70 percent of gas production capacity was out of service, and energy companies were forced to shut down more than 25 percent of the refining capacity in the United States (Tierney 2010 Wilbanks et al. 2007; Timmons and Bajaj 2005). To address these issues, energy suppliers in the Gulf are now moving administrative operations to less vulnerable areas, creating redundancy in their distribution chains, and employing more advanced management techniques to reduce their vulnerability to more intense or frequent storm events.

In order to come to a geographically appropriate understanding of climate impacts and adaptive strategies such as those identified in the Gulf and Northeast, operators and/or decision makers with influence over the system in question must be engaged in adaptation processes. These stakeholders are already intimately familiar with how weather affects their operations and can provide important insight into how changes in climate could exacerbate existing areas of concern or create new challenges. For example, engagement with water-resource managers at the 2009 National Adaptation Summit demonstrated that climate change is unlikely to pose many novel threats to water-quality issues, but instead is likely to compound existing stressors (e.g., flooding from combined sewer overflows, and hypoxic zones) (National Climate Adaptation Summit Committee 2010). With this knowledge, researchers can work collaboratively with water-resource managers to assess the composite threats of multiple stresses on issues such as water quality and seek robust solutions. Armed with such information, decision makers can then evaluate the costs, benefits, and risks of available options.

Such engagement is also pivotal for understanding the types of data and information that local stakeholders need to make appropriate decisions. By engaging 
users of information at the onset of research and data production, researchers can produce information that is scientifically sound and practically useful and useable by local stakeholders.

Moreover, close collaboration with sector-specific managers will help in identifying contextually relevant vulnerabilities and adaptation strategies that are responsive to the most up-to-date climate science. This is particularly important in cases where climate impacts are likely to differ from what has historically been experienced. For example, historic experience with flooding may prove insufficient for dealing with future increases in intensity and frequency of flooding. Developing water-supply or stormwater management systems based on the past 100 years will prove ineffective and inefficient. Having a close partnership between researchers, decision-makers, and members of the community can help provide timely, critical, and usable information that decision-makers need

\section{Adaptation across Sectors and Scales}

Adaptation actions that address issues in multiple sectors or at multiple scales are imperative for building resilience to climate change, particularly across large spatial scales. For example, the vulnerability of the transportation system-mobility by land, water, and air - to climate change can be addressed only by looking across geopolitical boundaries. Reliability of transportation corridors is essential to industrial supply chains, public transit systems, and freight mobility, for example. Moreover, disruption of transportation systems by climate change could indirectly impact food supply and quality, access to public services, energy supply, and social connectivity, thereby emphasizing the need for multi-sector adaptation efforts.

To date, many multi-sector adaptation efforts have focused on building geopolitical collaboration. The Southeast Florida Regional Climate Compact is one such example where four counties in southern Florida (Miami-Dade, Palm Beach, Monroe, and Broward) have partnered to develop a regional climate action plan that identifies strategies that all communities will undertake to simultaneously reduce their greenhouse gas emissions and build resilience to climate impacts (Southeast Florida Regional Climate Compact 2012a). One of the key components of their plan is their intergovernmental mode of operation and governance (Southeast Florida Regional Climate Compact 2012b). Examples of efforts successfully completed to date include creation of a regionally unified sea-level rise projection and 
vulnerability assessment, completion of a regional greenhouse gas emissions inventory, creation of a Regional Climate Action Plan, and joint legislative advocacy that led to an amended Florida law creating "Adaptation Action Areas," areas that are uniquely vulnerable to climate impacts (Southeast Florida Regional Climate Compact 2012a).

Another regional initiative focused on building resilience to climate change is the Western Adaptation Alliance (WAA). The WAA is a partnership between eleven municipalities in the Southwest and Great Plains aimed at enhancing tools, methods, and networking to assist in building resilience to the unique climate impacts of the American West (Institute for Sustainable Communities 2011). The concept for the WAA originated from a 2010 climate adaptation workshop hosted by the Institute for Sustainable Communities in Boston, MA (Institute for Sustainable Communities 2011). At this workshop, those from inland communities realized that most of the climate adaptation efforts to date had focused on sea-level rise, leaving them without the information, resources, and support they needed to deal with climate challenges such as increased temperatures, precipitation changes, and changes in water supply and quality. Stakeholders from these inland communities banded together and formed the WAA as a mechanism for sharing best practices and lessons learned, providing inter-municipal support for climate adaptation efforts, and building mutually reinforcing support systems. To date, members of WAA have created a shared regional vision for adaptation, have created three regional and sub-regional projections of climate change to guide individual municipal action, and continue to meet monthly via group conference calls (Institute for Sustainable Communities 2013).

The WAA and the Southeast Florida Regional Climate Compact are two examples of regional, geopolitical collaborations that stemmed from stakeholders realizing that existing institutional structures and support systems did not meet their needs. In both cases, stakeholders banded together with nonprofit organizations, federal agencies, and/or academic institutions to find alternative means of meeting their needs. These examples demonstrate the importance of multi-jurisdictional collaboration on issues that cross political boundaries, address multiple systems, and demand a combination of local stakeholder knowledge and scientific information.

Working across sectors is also important when attempting to identify regional vulnerabilities and appropriate strategies to prepare for climate change. For example, warmer temperatures could lead to lower Great Lakes water levels because lake ice cover will be reduced in the winter months and evaporation will increase in the summer months. However, if a community looked only at how this might impact 
drinking water, it would miss a suite of other impacts associated with declining water levels such as impacts on shipping, lakefront development, fisheries, tourism, energy, water quality, public health, and the economy.

Looking at climate impacts through a narrow lens can lead communities to identify maladaptive strategies, that is, strategies that could address one aspect of a changing climate but create additional risks. For example, seeking to increase land cover with cellulosic biofuel crops could help to meet goals pertaining to alternative fuels, but it could also increase water demand or fragment habitats needed for species migrations as ecosystems shift. The need for robust solutions to a panoply of climate changes within a system or region further underscores the importance of engaging all stakeholders in adaptation processes so that conflicting and complex interests can be openly discussed, negotiated, and balanced in contextually appropriate ways.

\section{Efforts Underway and Lessons to Be Learned}

A recent analysis found that adaptation efforts are underway in all regions and sectors of the United States (Bierbaum et al. 2013). However, the types of actions and the motivations behind them vary quite significantly across sectors, regions, and scales (Carmin, Nadkarni, and Rhie 2011; Bierbaum et al. 2013). In Groton, Connecticut, climate-adaptation efforts looked solely at how sea-level rise could affect the community's overall economic and cultural vitality (Stults and Pagach 2011). Denver, Colorado initiated its climate adaptation efforts by focusing on how climate change could affect the city and broader region's water supply and quality. After years of working to build the resilience of the water system to climate change, the city is now looking more holistically at how climate change could affect nearly all social, built, natural, and economic systems within the community.

In contrast, Keene, New Hampshire, touted as the first community to develop an official climate adaptation plan, began its climate adaptation work by looking at how climate change would affect all government departments, focusing on strategies to address internal vulnerability to climate change (City of Keene 2012). Grand Rapids, Michigan has worked to integrate climate-change concerns into the community's larger sustainability plan, which serves as the community's comprehensive plan, guiding all governmental decisions pertaining to future growth and development (City of Grand Rapids 2012). In New York City, PlaNYC is the city's official sustainability plan, establishing goals, targets, milestones, and points of responsibility for city-wide 
efforts to enhance economic, environmental, and equity concerns (City of New York 2012). Created with the input of hundreds of stakeholders, PlaNYC is perhaps the most comprehensive plan to address climate change in tandem with other stressors such as population growth, economic challenges, urban decline, and social justice.

As illustrated above, communities can initiate their climate adaptation efforts in numerous ways (Bierbaum et al. 2013). Communities across the United States have employed diverse strategies, such as focusing on internal operations, starting with a sector that is particularly vulnerable, integrating climate change concerns into existing planning approaches, and conducting a community-wide assessment. The results from these experiments demonstrate that there is no "one size fits all" adaptation process or adaptation action. However, there are similarities in information needs and approaches across regions and sectors. Therefore, strategies that promote the sharing of best practices and data, learning by doing, and achieving successes through iterative and collaborative processes will be crucial in jumpstarting adaptation actions across the country.

The sharing of lessons learned and best practices requires effective stakeholder engagement. At a recent conference held at the Garrison Institute, communities from around the country discussed the challenges they faced in meaningfully engaging a diverse array of community stakeholders in efforts to create more resilient and sustainable local communities (Garrison Institute 2013). This discussion centered on the importance of getting an appropriate cross-section of people engaged in evaluating and choosing adaptations, realizing that there is no single solution and decisions will need to be revisited over time. To succeed, communities must use contextually relevant processes and engagement techniques. Collaborations between managers, planners, researchers, nonprofits, members of the community, and others throughout a project's lifecycle appear to enhance success. In particular, working with stakeholders to identify barriers to action and working collectively to eliminate or reduce those barriers is essential. When possible, finding ways that climate change adaptation can meet other societal goals such as sustainable development, hazard risk reduction, or improved quality of life can be an effective strategy for building community support and fostering non-traditional stakeholder engagement.

\section{Ways Forward}

While adaptation plans and initial implementation actions have begun to proliferate in recent years across the United States, the field of adaptation is still quite 
nascent compared to that of mitigation. And, unfortunately, a number of barriers are constraining climate adaptation action, principally lack of available technology/decision support tools, institutional barriers and limited information. The federal government, research institutions such as universities, boundary organizations, and community groups must play a key role in making further progress on adaptation as soon as possible.

\section{Technology / Decision Support Tools}

It is clear that water intake pipes, combined sewer overflows, levee levels, transmission lines, reservoirs, maintenance plans, and power-plant design and management may all need to be altered as climate changes. Additionally, rules for managing Great Lakes water levels, reservoir levels, and dam-dredging times will need revision. Surveillance for disease outbreaks and extreme events such as floods, droughts, and heat waves will need to be heightened, and new tools to characterize "break-points" in management and infrastructure must be developed and shared. Experts from public health, engineering, natural resources, planning, transportation, and policy will be needed to design and evaluate appropriate tools, technologies, policies, and management responses. Current best practices for disaster preparedness, recovery from floods and hurricanes, heat stress management, and drought planning should be assembled and shared across regions to help define "Climate Resilient Communities." It may be possible to create "buddy systems," that is, to link cities, watersheds, and ecological zones with similar regions to jointly find solutions. National and regional clearinghouses for such best practices are needed, and existing networks could be networked. Building blocks could include the existing Agricultural Extension services, the Sea Grant Programs, and the Regional Integrated Science Assessments (RISAs) of the Department of Commerce-all of which combine federal and university expertise.

\section{Institutional Barriers}

Climate change will not only affect natural ecosystems and infrastructure, it will also stress existing social, institutional, and legal arrangements. As stream water flows change due to a changing hydrological cycle, Total Maximum Daily Loads (TMDLs), a key component of the Clean Water Act that depends on flow, will need to be recalculated. Building codes (and landscaping provisions) will need to be updated not only for energy efficiency, but also to protect against disease vectors, reduce susceptibility to heat stress, and improve protection against extreme events 
such as high winds and storm surge. National and international jurisdictional issues present challenges in replumbing the Great Lakes to mitigate reduced lake levels, managing the Columbia River to adapt to declining snowpack, or managing the Colorado River to deal with drought. Both bottom-up community planning and top-down response strategies will be needed to help regions deal with increases in brownout, heat stress, floods, and wildfires. Increasingly, national, state, and local operational agencies will need to incorporate climate risks and adaptation planning into their programs and operations.

The mix of necessary changes to adapt zoning laws and building codes to climate change varies greatly around the United States, depending on a region's vulnerability. The authority to undertake needed changes also varies among levels of government. This disconnect provides a rich opportunity for architecture, planning, and policy experts to collaborate in both university and government settings to ameliorate these existing barriers and devise solutions to building institutional resilience to climate change.

\section{Limited Information}

There is still a great need for basic and applied research, some of which is documented in the previous NCAs, the two Summits, and the US Global Change 10year plan (US Global Change Research Program 2012; Bierbaum, Brown, MacAlpine 2007; Bierbaum et al., 2007). For example, very little is known about managing the resources of an acidifying ocean. Similarly, regional-scale analyses of impacts need to be conducted, refined, and repeated at regular intervals. We need to understand the costs of adapting and the costs of not adapting. We need to understand whether there are limits to adaptation. How can we best develop adaptation strategies for systems in flux? How might actions taken to reduce-or mitigate-emissions interact with the options available to adapt? It is also becoming increasingly important to apply social and behavioral research in adaptation decision making, since technological options or planning and management practices that no one wants to implement are not feasible choices; decision makers must therefore consider societal ideas, input, and preferences

\section{Evaluating Success}

Finally, how can increasing resilience or robustness to climate change be evaluated? What does success mean? A system for evaluating the effectiveness of climate 
adaptation processes and actions is needed to gauge progress and change course as needed. To date, very little evaluation of the effectiveness of climate adaptation has been undertaken because little actual implementation of adaptation plans has taken place, and comprehensive evaluation metrics do not exist.

And of course, many local communities lack the internal capacity to undertake all of the actions needed to build resilience to climate change. Lack of funding and support from leadership, competing priorities, and lack of staffing capacity are all barriers that are limiting and in some cases preventing local communities from meaningfully moving forward with climate action (Carmin, Nadharni, and Rhie 2011).

\section{Conclusion}

In conclusion, national action on adaptation to climate change is overdue and desperately needed to protect people and resources in the coming decades. The good news is that characterizing vulnerability to climate change by region and sector has been — and is being — advanced by a number of efforts, including periodic NCAs. In recent years, communities across the United States and federal agencies have begun to think seriously about increasing resilience to climate change and options that can be implemented. What is needed, however, is the quick development of decision-support tools and aggregate best practices, as well as the alleviation of barriers to implementation of wise technologies and policies so that adaptation to climate change becomes a normal part of all planning and management activities. However, context for adaptation will always be key. Adaptation actions must be framed within the geographic, socio-economic, and cultural contexts of the communities within which they will be implemented to be successful and sustainable. This necessitates engaging local stakeholders in processes to identify a vision of resilience, impediments to achieving that vision, and contextually relevant actions for achieving that vision.

\section{References}

Arbor Day Foundation. "Differences between 1990 USDA Hardiness Zones and 2006 arborday. org Hardiness Zones Reflect Warmer Climate.”Accessed January 15, 2013. http://www.arborday.org/media/map_change.cfm and http://planthardiness.ars.usda.gov/PHZMWeb/. 
Bierbaum, Rosina, Joel Smith, Arthur Lee, Maria Blair, Lynne Carter, F. Stuart Chapin III, Paul Fleming, Susan Ruffo, Shannon McNeeley, Missy Stults, Emily Wasley, and Laura Verduzco. 2013. "A Comprehensive Review of Adaptation in the United States: More Than Before, But Less Than Needed." Mitigation and Adaptation Strategies for Global Change 18 (13): 361-406. http://dx.doi.org/10.1007/s11027-012-9423-1

Bierbaum, Rosina M., John P. Holdren, Michael C. MacCracken, Richard H. Moss, and Peter H. Raven, eds. 2007. Confronting Climate Change: Avoiding the Unmanageable and Managing the Unavoidable. Washington, DC: The United Nations Foundation, 166.

Bierbaum, Rosina, Dan Brown, and Jan McAlpine, eds. 2007. Coping with Climate Change: National Summit Proceedings. Ann Arbor: University of Michigan/Island Press, 256.

Carmin, JoAnn, Nikhil Nadkarni, and Christopher Rhie. 2011. "Progress and Challenges in Urban Climate Adaptation Planning: Results of a Global Survey." Massachusetts Institute of Technology, 33.

Centers for Disease Control and Prevention. "Climate Change and Health Program." Accessed March 28, 2013. http://www.cdc.gov/climateandhealth/effects/default.htm.

City of Grand Rapids. "Sustainability Plan: As Amended June 21, 2011.” Accessed December 15, 2012. http:/grcity.us/enterprise-services/officeofenergyandsustainability/Documents/ Sust\%20Plan\%20as\%20amended\%206-21-11.pdf .

City of Keene, New Hampshire. "Keene Comprehensive Master Plan." Accessed December 15, 2012. http://www.ci.keene.nh.us/departments/planning/master-plan-process/cmp-resources.

City of New York. "PlaNYC: Progress Report 2012-A Greener, Greater New York." Accessed December 15, 2012. http://nytelecom.vo.llnwd.net/o15/agencies/planyc2030/pdf/PlaNYC_ Progress_Report_2012_Web.pdf.

Energy and Environmental Analysis, Inc. Foundation. 2005. "Hurricane Damage to Natural Gas Infrastructure and its Effects on the U.S. Natural Gas Market." Arlington, VA: The Energy Foundation, Inc., 49.

Few, Roger, Katrina Brown, and Emma L. Tompkins. 2007. "Public Participation and Climate Change Adaptation: Avoiding the Illusion of Inclusion." Climate Policy 7: 46-59.

Frumhoff, Peter, James McCarthy, Jerry Melillo, Susanne Moser, and Don Wuebbles, eds. 2007. Northeast Climate Impacts Assessment. Confronting Climate Change in the Northeast: Science, Impacts, and Solutions. Cambridge, MA: Union of Concerned Scientists, 160.

Garrison Institute. 2013. Climate, Cities, and Behavior Symposium Proceedings. Garrison, New York: Garrison Institute.

Gifford, Robert. 2011. "The Dragons of Inaction: Psychological Barriers That Limit Climate Change Mitigation and Adaptation." American Psychologist 66:290. http://dx.doi.org/10.1037/ a0023566

Institute for Sustainable Communities. 2011. "Climate Adaptation and Resilience: A Resource Guide for Local Leaders.” Montpelier, VT: Institute for Sustainable Communities, 107. 2013. "Forwarding Adaptation in the Great Lakes Region: A Resource Guide for Local Leaders." Montpelier, VT: Institute for Sustainable Communities.

Intergovernmental Panel on Climate Change. 2007. Climate Change 2007. Cambridge, U.K., and New York, NY: Cambridge University Press, 976.

2012. Managing the Risks of Extreme Events and Disasters to Advance Climate Change Adaptation-A Special Report of Working Groups I and II of the Intergovernmental Panel on Climate Change. Cambridge, U.K., and New York, NY: Cambridge University Press, 20. 
Karl, Thomas R., Jerry M. Melillo, and Thomas C. Peterson, eds. 2009. Global Climate Change Impacts in the United States. Cambridge: Cambridge University Press, 196.

Morgan, Granger, Jay Apt, and Lester Lave. 2005. The U.S. Electric Power Sector and Climate Change Mitigation. Washington, DC: Pew Center for Global Climate Change, 95.

NASA. "Global Warming Page." Accessed January 2, 2013. http://earthobservatory.nasa.gov/Features/GlobalWarming/page2.php.

National Climate Adaptation Summit Committee. 2010. National Climate Adaptation Summit Report. Ann Arbor: University of Michigan, 26.

National Research Council. 2010. Advancing the Science of Climate Change: America's Climate Choices. Washington, DC: National Research Council,,528.

National Wildlife Federation. 2007. "The Gardener's Guide to Global Warming: Challenges and Solutions." Reston, VA: The Wildlife Federation, 40.

NOAA (National Oceanic and Atmospheric Administration). "National Climatic Data Center." Accessed March 28, 2013. http://www.ncdc.noaa.gov/news/ncdc-announces-warmest-yearrecord-contiguous-us.

Potsdam Institute for Climate Impact Research and Climate Analytics. 2012. Turn Down the Heat: Why a $40 C$ Warmer World Must Be Avoided, A Report for the World Bank. Washington, DC: The International Bank for Reconstruction and Development/The World Bank, 106.

Solecki, William, and Cynthia Rosenzweig. 2012. U.S. Cities and Climate Change: Urban, Infrastructure, and Vulnerability Issues. Technical Report in Support of the National Climate Assessment. Washington, DC: US Global Change Research Program, 191.

Southeast Florida Regional Climate Compact. 2012a. "A Region Responds to Climate: Southeast Florida Regional Climate Change Compact Counties Regional Climate Change Action Plan.” Southeast Florida, 84.

. 2012b. "Southeast Florida Climate Compact Website.” Accessed December 31, 2012.

Stults, Missy, and Jennifer Pagach. 2011. "Preparing for Climate Change in Groton, Connecticut: A Model Process for Communities in the Northeast." Hartford, CT: Connecticut Department of Environmental Protection, 20.

Tierney. Susan. 2010. "Adaptation and the Energy Sector" (presentation at the Coping with Climate Change National Summit, May 8-20, 2010).

Timmons, Heather, and Vikas Bajaj. 2005. "BP Details its Damages from Hurricanes." The New York Times, October 4, 2005, page C1.

UK Meteorological Office. “Global Temperatures in 2012.” Accessed January 2, 2013. http://www. metoffice.gov.uk/news/releases/archive/2012/global-temperatures-2012.

US Climate Change Science Program. Effects of Climate Change on Energy Production and Use in the United States. A Report by the U.S. Climate Change Science Program and the Subcommittee on Global Change Research. Washington, DC: US Department of Energy, Office of Biological and Environmental Research, 96.

US Global Change Research Program. 2000. National Assessment of the Potential Consequences of Climate Variability and Change. Washington, DC: US Global Change Research Program, 152. 2012. "The National Global Change Research Plan 2012-2021: A Strategic Plan for the U.S. Global Change Research Program.” Washington, DC: US Global Change Research Program, National Coordination Office.

2013a. Draft. The 2013 U.S. National Climate Assessment. Washington, DC: US Global Change Research Program. 
. 2013b. "Introduction to National Climate Assessments." Accessed January 2, 2013. http:// www.globalchange.gov/what-we-do/assessment/previous-assessments/the-first-nationalassessment-2000.

US Global Change Research Act. "Public Law 101-606.” Accessed December 15, 2012. http:// www.gcrio.org/gcact 1990.html. .

Van Aalst, Maarteen K., Terry Cannon, and Ian Burton. 2008. "Community Level Adaptation to Climate Change: The Potential Role of Participatory Community Risk Assessment." Global Environmental Change 18:165-179. http://dx.doi.org/10.1016/j.gloenvcha.2007.06.002

White House. "Climate Change Adaptation Task Force." Accessed December 28, 2012. http:// www.whitehouse.gov/administration/eop/ceq/initiatives/adaptation.

Wilbanks, Tom, Vatsal Bhatt, Daniel E. Bilello, Stanley R. Bull, James Ekmann, William C. Horak, Y. Joe Huang, Mark D. Levine, Michael J. Sale, David K. Schmalzer, and Michael J. Scott, eds. 2007. Effect of Climate Change on Energy Production and Use in the United States: Synthesis and Assessment Product 4.5. Washington, DC: US Department of Energy, Office of Biological and Environmental Research, 160.

World Bank. 2010. World Development Report 2010: Development and Climate Change. Washington, DC: The International Bank for Reconstruction and Development/The World Bank. 